\title{
MORTALIDADE PRECOCE DAS EMPRESAS DO RAMO DE PET SHOP
}

\section{ARTIGO ORIGINAL}

FERREIRA, Roberto Soares Martins ${ }^{1}$

ROCHA, Arnaldo ${ }^{2}$

FERREIRA, Roberto Soares Martins. ROCHA, Arnaldo. Mortalidade precoce das empresas do ramo de pet shop. Revista Científica Multidisciplinar Núcleo do Conhecimento. Ano 04, Ed. 09, Vol. 01, pp. 116-139. Setembro de 2019. ISSN: 24480959, Link de acesso: https://www.nucleodoconhecimento.com.br/veterinaria/mortalidade-precoce

\section{RESUMO}

O Brasil, quarto país em população animal do mundo, é também o segundo colocado mundial no mercado pet, perdendo somente para os Estados Unidos. Cerca de 90\% dos lares brasileiros possuem algum animal de estimação, como cão e gato, sendo que do total de 8000 pets do estado de São Paulo, 62,5\% estão na cidade de São Paulo. A Associação Brasileira da Indústria de Produtos para Animais de Estimação (ABINPET,2013) estima um aumento de 9,2\% em relação a 2013, consolidando o país como segundo mercado mundial, perdendo apenas para os Estados Unidos. Em um mercado promissor como este por que ocorre a mortalidade de empresas do ramo? Quais os principais desafios e como contorná-los? O que é necessário fazer para que empreender neste mercado seja algo sustentável ao longo do tempo e quais os pontos devem ser considerados é o que se deseja abordar neste artigo.

Palavras-chave: Empresa Pet, falência, fechamento.

${ }^{1}$ Graduado em Medicina Veterinária.

2 Doutor em Medicina Veterinária. 


\section{INTRODUÇÃO}

A expressão pet tem origem na língua inglesa e é amplamente utilizada no âmbito de vendas, marketing e mídia, sendo referente a animais de estimação, os quais são criados em convívio com o homem, em sua rotina domiciliar, são inseridos na família e assim são benéficos pelas relações afetivas estabelecidas. Dentre as espécies inclusas nessa categoria, podem ser citados os cães, gatos, aves canoras e ornamentais, pequenos roedores, peixes, cobras, répteis, entre outros. O destaque para essa relação entre animal e pet, está vinculada a rastreabilidade do proprietário na criação do mesmo, além do contato de ambos (ELIZEIRE, 2013). Segundo (AFONSO, 2008), ao tratar do mercado voltado para produtos e serviços destinados aos cuidados de animais de estimação, demonstra que o mesmo tem apresentado crescimento e merecido destaque em todo o mundo pela relevância em termos de lucratividade. No Brasil, pode-se observar a importância econômica que os pet shops têm demonstrado, o que é acarretado consequência ao êxito obtido por parte dos empreendedores. Esse fato se deve ao aumento na criação de animais de estimação que implica a necessidade de atendimento e cuidados específicos para essa categoria, o que acaba por atrair novos investidores. Assim, com o aumento da concorrência, existe então o dever de conciliar novos método e vantagens para trazer novos clientes e fidelizar os antigos (ELIZEIRE, 2013). Para que o empreendedor consiga conquistar o espaço e estabelecimento no segmento, é relevante que o mesmo esteja alerta ao progresso quanto ao perfil dos consumidores e as mudanças que acontecem no mercado (ELIZEIRE, 2013). Desta forma, consideraremos os dados de pesquisa e uma análise SWOT para apoiar a construção dos pontos relevantes que devem ser observados em termos de fraquezas, ameaças, oportunidades e forças para empreender com sustentabilidade neste mercado, possibilitando:

- Maior segurança para a tomada de decisão

- Conhecimento mais aprofundado do cenário

- Compreensão sobre os concorrentes

- Conhecimento de movimentos externos 
- Indicações de alternativas de ação

Conforme (CASAROTTO, 2018), SWOT em inglês é a sigla para Forças (Strengths), Fraquezas (Weakness), Oportunidades (Opportunities) e Ameaças (Threats).

No Brasil, algumas pessoas chamam essa análise de FOFA (Forças, Ameaças, Fraquezas e Oportunidades), tradução adaptada do SWOT. Provavelmente criada na década de 60, na Universidade de Stanford (EUA), foi gerada a partir do estudo das 500 maiores empresas norte-americanas da época, tornando-se, desde então, numa das metodologias clássicas da Administração.Esta análise é utilizada normalmente para o planejamento, pois se resume na realização de um diagnóstico completo, sobre o mercado, comportamento do consumidor, fornecedores e concorrência e ambiente que o cerca. Sendo assim, passamos a organizar a estrutura de capítulos considerando os objetivos, cenário atual, desenvolvimento e análise swot, relato de caso, conclusão, considerações finais, referências e anexos.

\section{REVISÃO DE LITERATURA}

Para melhor compreendermos o segmento pet é necessário termos uma visão sobre os principais números do mercado brasileiro neste setor e conhecermos um pouco sobre quem são os "atores" deste mercado.Para tanto, seguiremos com informações relevantes para todo empreendedor que desejar adentrar neste mercado.

\section{MERCADO}

Segundo últimos dados divulgados pela (ABINPET, 2013) (Associação Brasileira de produtos para animais de estimação, 2013), IBGE (Instituto Brasileiro de Geografia e Estatística) e a empresa Euromonitor International, especialista em pesquisas de mercado e parceira das anteriores no Brasil, o cenário mundial de pets tem sua população distribuída conforme abaixo (ABINPET,2013) 
(Figura 1): Cenário Mundial de população Pet

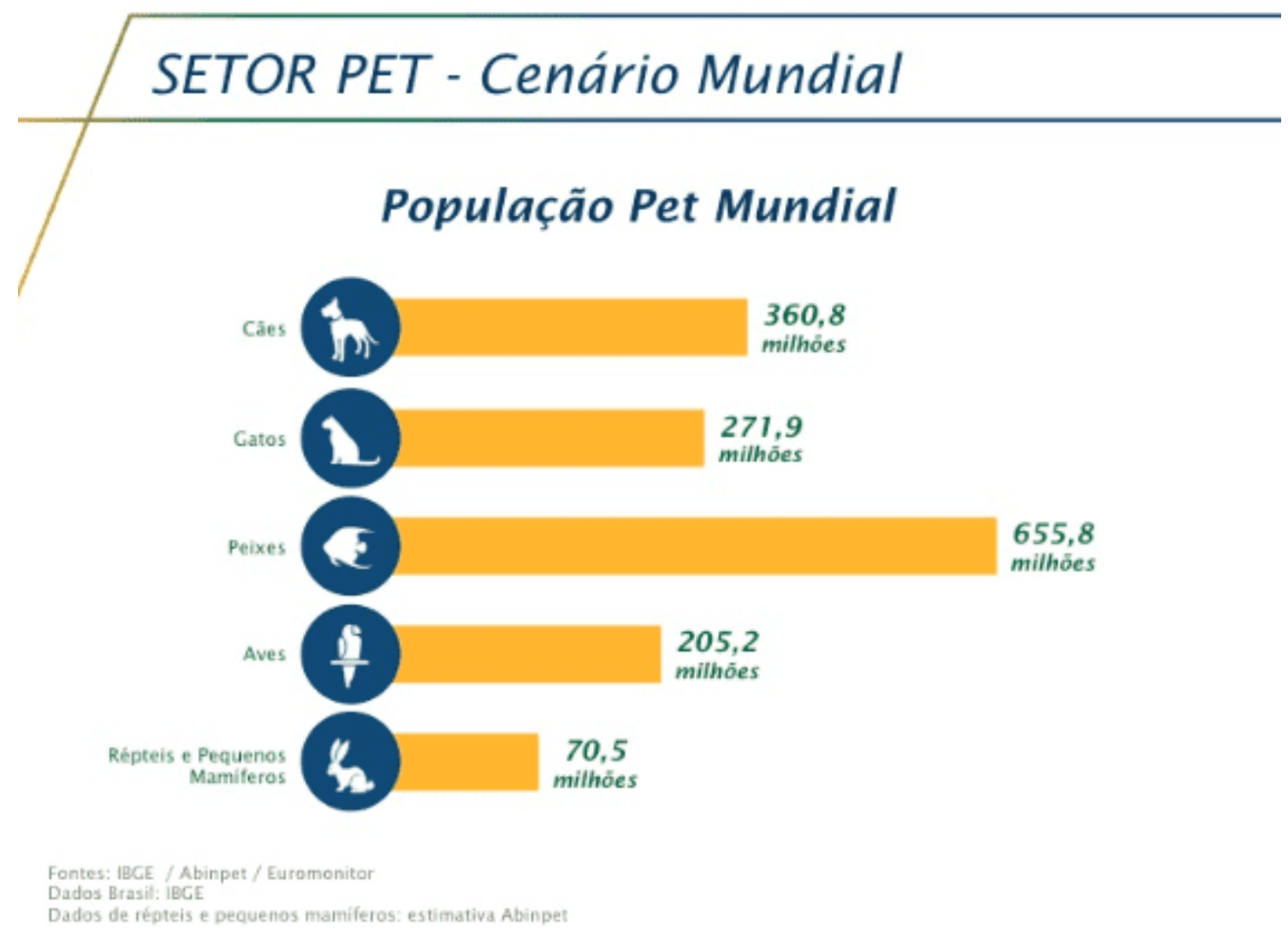

Fonte: IBGE/ABINPET/EUROMONITOR 2013

A mesma pesquisa, demonstra que no Brasil possui a segunda maior população de cães, gatos, aves canoras e ornamentais, o terceiro maior faturamento do mundo no segmento e a quarta posição do mundo em população total de animais de estimação independente da espécie. 
(Figura 2): Cenário Brasileiro de população Pet
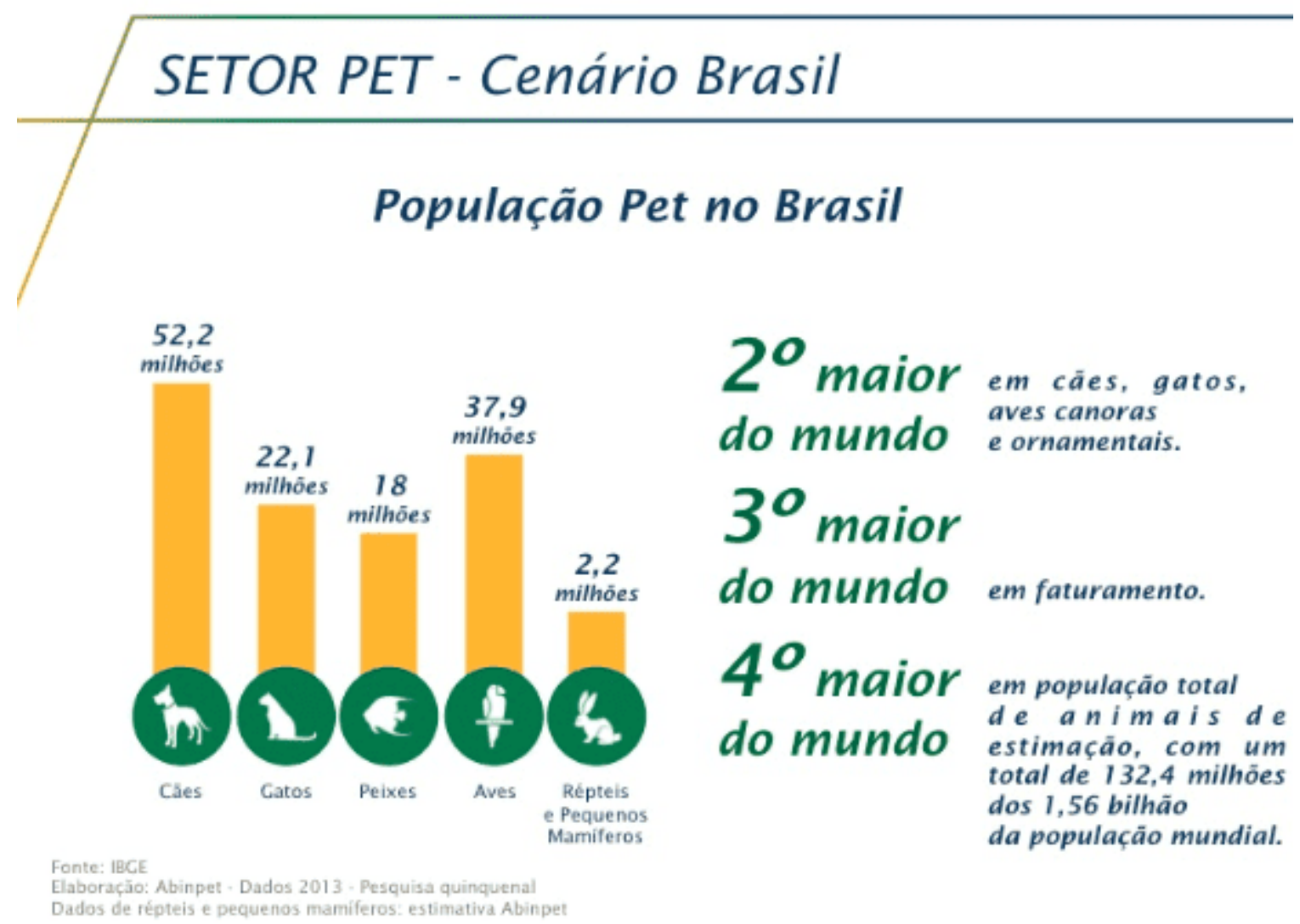

20 maior em cäes, gatos, do mundo aves canoras

$3^{\circ}$ maior do mundo em faturamento.

40 maior em população total do mundo de an i mais de total de 132,4 milhöes dos 1,56 bilhão da população mundial.

Em termos de faturamento, em 2016 observou-se crescimento de quase 5\% sobre os 18 bilhões de faturamento anual de 2015, sendo que o mercado de Pet Vet chegou a quase $7 \%$, seguido pelo Pet Care com 5,5\% e Pet Food com 4,9\% de crescimento no mesmo período. 
(Figura 3): Faturamento Brasileiro em produtos e serviços Pet

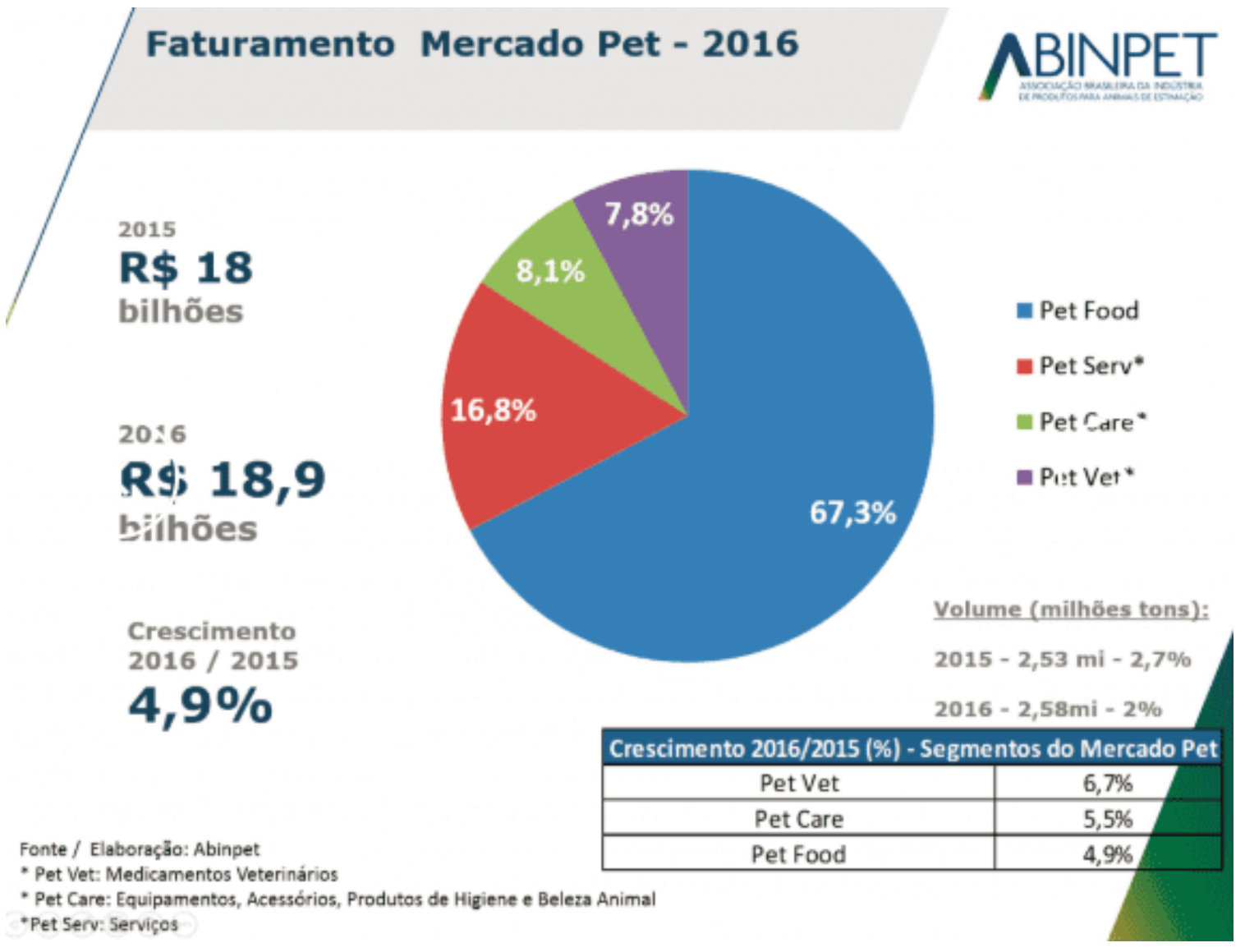

Fonte: ABINPET 2016

Conforme Polli.M.(REVISTA EXAME, 2017), dados mais recentes da ABINPET (Associação Brasileira de produtos para animais de estimação) mostram que de Janeiro a Julho de 2018 o Paraguai foi o maior importador de produtos Pet do mercado brasileiro, cuja indústrias como Royal Cannin e Zoetis, movimentou neste mesmo período cerca de US\$ FOB 119,62 milhões.O ranking é liderado pelo Paraguai, com US\$ FOB 19,6 milhões, seguido por Hong Kong (US\$ FOB 16 milhões), Uruguai (US\$ FOB 10,8 milhões), Estados Unidos (US\$ FOB 8,8 milhões, e maior mercado mundial) e Chile (US\$ FOB 7,8 milhões). O resultado parcial deste ano reforça a importância do intercâmbio comercial com os países da América Latina, cujos dados são levantados pela Agência Brasileira de Promoção de Exportações e Investimentos (Apex-Brasil).Há que se conhecer e compreender os impactos diretos que a carga tributária representa no setor.Muitos empreendedores não consideram esta 
informação como sendo relevante e por vezes esta pode ser uma das causas de maior influência no sucesso ou insucesso de um projeto nesta área.Vejamos como se comporta a carga tributária, conforme dados da (ABINPET,2016) (Associação Brasileira de produtos para animais de estimação):

(Figura 4): Carga tributária no Brasil

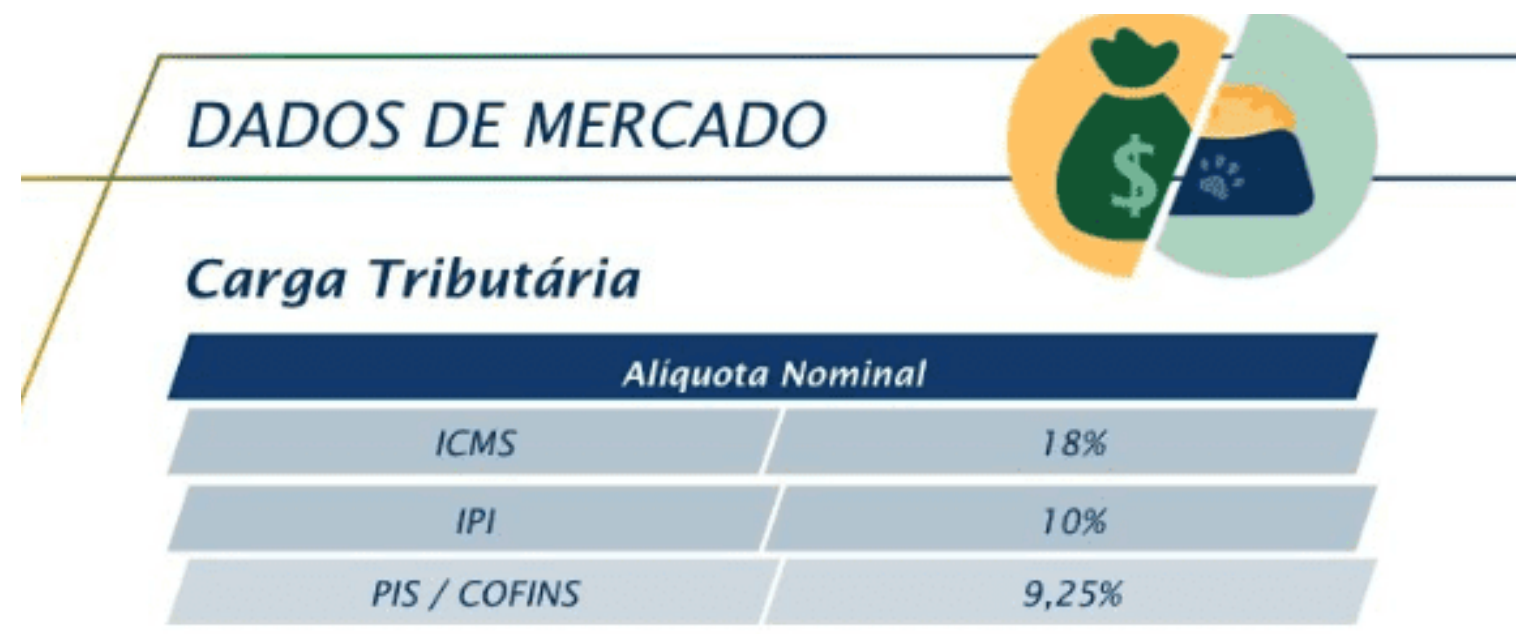

Aliquota Efetiva

\begin{tabular}{|c|c|}
\hline ICMS & $24,74 \%$ \\
\hline IPI & $13,75 \%$ \\
\hline PIS / COFINS & $12,71 \%$ \\
\hline Carga Total & $51,20 \%$ * \\
\hline sobre preco base da indústria (preço + margem) / Com o Estado da Federaça/ $/$ & Atualizaçäo: LCa Consultoria. \\
\hline gime tributario da empresa.
\end{tabular}

Fonte: ABINPET/LCA consultoria

Conforme estudo realizado pelo SEBRAE em outubro de 2016, considerando aas empresas brasileiras constituídas em 2012 disponíveis na Secretaria da Receita Federal até 2014, a taxa de sobrevivência das empresas com até dois anos de atividade foi de $76,6 \%$ (SEBRAE,2016) 


\section{CONSUMIDORES}

Por parte do empreendedor, para que este consiga conquistar o espaço e estabelecimento no segmento, é relevante que o mesmo esteja alerta ao progresso quanto ao perfil dos consumidores e as mudanças que acontecem no mercado (ELIZEIRE, 2013).

No ano de 2016, aproximadamente:

- $44,3 \%$ dos domicílios brasileiros possuíam ao menos um cão (52 milhões de animais aproximadamente)

- $17,7 \%$ equivalia a felinos (22,1 milhões de animais)

Os brasileiros gastam cerca de 18 bilhões de reais por ano em produtos e serviços para animais. Igualmente importante é conhecer o perfil dos tutores de pets no Brasil para compreender hábitos e comportamentos de consumo. De acordo com a revista (EM NACIONAL,2016) uma pesquisa feita em 2016 pela Faculdade de Medicina Veterinária da Universidade de São Paulo (USP), o perfil dos tutores pode ser relacionado como o disposto a seguir. Em se falando de tutores de cães, o perfil se caracteriza temos que: Proprietários de cães são, em sua maioria (51\%), casados. (EM NACIONAL,2016)

- Donos de cães têm, em média, 41 anos, e 93\% moram com mais de uma pessoa.

- $82 \%$ dos proprietários de cachorros são de classe AB (na classe A, são 24\%);

- $59 \%$ moram em casas.

- $24 \%$ adotaram seus cães, sendo $59 \%$ deles sem raça definida.

- $44 \%$ veem seus cachorros como filhos - a maioria dos que têm essa opinião é mulher solteira de até 40 anos.

- $64 \%$ dos entrevistados deixam os cães dormirem dentro de casa.

Já os tutores de gatos possuem as seguintes características:

- $61 \%$ dos donos de gatos são mulheres. 
- $48 \%$ acreditam que os felinos entendam o humor dos donos.

- $45 \%$ veem seus gatos como filhos.

- Os donos de gatos têm em média 40 anos;

- $62 \%$ moram em casas.

A maioria dos que têm a visão de que gatos são como filhos é mulher solteira de até 40 anos. Um dado bastante curioso é que, segundo esta mesma pesquisa, proprietários de gatos levam menos os pets ao médico veterinário: uma média de 2,3 vezes por ano, contra 2,8 no caso dos donos de cachorros. Já das pessoas entrevistadas que não possuem pets, a pesquisa mostra que:

- $100 \%$ têm vontade de comprar ou adotar um animal de estimação;

- $90 \%$ pretendem adquirir um cão;

- $20 \%$ pretendem adquirir um gato.

- $47 \%$ dos que não têm pets apresentam, em média: 37 anos

- $25 \%$ moram com filhos de até 9 anos

- $57 \%$ moram em apartamento

- $94 \%$ já tiveram um animal de estimação antes.

Se considerarmos os números propícios de crescimento em taxa de $5 \%$ ao ano, o tamanho da população pet e perfil dos consumidores, os números relacionados a faturamento e os horizontes de exportação dos produtos do mercado brasileiro, certamente há que se concluir que se trata de um segmento fértil e que ainda apresenta grande potencial para ser amplamente explorado. Todavia, o nosso foco é possibilitar que o empreendedor tenha capacidade de tomar uma decisão minimamente segura considerando não somente as vantagens mercadológicas, mas em especial as dificuldades que o setor pode apresentar ao longo de um período mínimo de crescimento de um novo empreendimento. Segundo dados reportados por estudo realizado pelo Serviço Brasileiro de Apoio às Micro e Pequenas Empresas (SEBRAE, 2016), para as empresas brasileiras constituídas em 2012 (disponíveis na Secretaria da Receita Federal até 2014), a taxa de sobrevivência das empresas com até dois anos de atividade foi de 76,6\%. (SEBRAE,2016).A partir disso, surge então o questionamento: em um mercado promissor, como este por que ocorre a mortalidade 
de empresas do ramo? Como pudemos observar $23 \%$ dos empreendimentos neste mercado acabam em insucesso num prazo não maior que dois anos. Diversos fatores estão envolvidos na questão da falência de empresas no Brasil, não somente no setor PET, entre elas:

- falta de planejamento

- má gestão e administração do negócio

- carga tributária empresarial brasileira

- Surgimento de grandes cadeias lojas no ramo de Pets. (EM NACIONAL,2016)

Além dos fatores supracitados, com expansão desse segmento, aumenta também a necessidade de especializações que possam abranger princípios de marketing veterinário. Dessa maneira, há possibilidade de explorar ferramentas que se tornam primordiais para melhor desenvolvimento e gerenciamento das atividades desenvolvidas nos estabelecimentos veterinários, marketing pessoal, gestão adequada de funcionários, conhecimento quanto a concorrência, o que compreende não apenas o profissional veterinário responsável, mas também toda a equipe de trabalho e representação comercial (ELIZEIRE, 2013). Ciência quanto ao marketing é imprescindível ao profissional atuante no mercado de trabalho e empresas que tem por finalidade o crescimento, em especial para as que objetivam a prestação de serviços com excelência, visando a satisfação de clientes e consumidores (ELIZEIRE, 2013). Nos dias atuais, observa-se mudança no comportamento das pessoas ao se tratar dos animais, e com isso há no mercado ascensão e maior investimento nesse seguimento. Outro ponto, é a humanização dos animais, que contribui para aumento no consumo dos produtos próprios para pets e o serviço que é prestado aos donos desses (ELIZEIRE, 2013). Proprietários caninos, costumam gastar em média $\mathrm{R} \$ 300,00 /$ mês; enquanto proprietários de felinos em média gastam $R \$ 120,00$. Os mesmos tratam os pets como parte da família: metade dos donos de cães diz ter relação de pai e filho com o animal, o que explica o alto investimento em saúde animal (ABINPET, 2018). Segundo estudo mais recente efetuado pelo Núcleo de estudos e pesquisa do (SEBRAE,2016) em outubro de 2016 sobre sobrevivência de empresas, a prestação de serviços em Higiene e embelezamento de animais domésticos, 
constituídas em 2012, foi equivalente a um total de aberturas 3,318 taxa de sobrevivência $80 \%$ em 3 anos. Na cidade de São Paulo, foram abertas aproximadamente 150.465 mil empresas, no ano de 2012. E ainda de acordo o SEBRAE (2016), a taxa de sobrevivência foi de $75,3 \%$. Na Tabela 1 é apresentado a taxa de sobrevivência e mortalidade de empresas entre os anos de 2008 a 2012. (SEBRAE,2016)

Tabela 1 - Estudo realizado entre 2008 e 2012.

\begin{tabular}{|l|l|l|l|l|l|}
\hline Parâmetro & 10 ano & 2o ano & 30 ano & $4^{\circ}$ ano & 50 ano \\
\hline Taxa de sobrevivência & $54,2 \%$ & $55,4 \%$ & $76,2 \%$ & $75,8 \%$ & $76,6 \%$ \\
\hline Taxa de mortalidade & $45,8 \%$ & $44,6 \%$ & $23,8 \%$ & $24,2 \%$ & $23,4 \%$ \\
\hline
\end{tabular}

Fonte: Autor.

Gráfico 1 - Taxa de mortalidade e sobrevivência de empresas

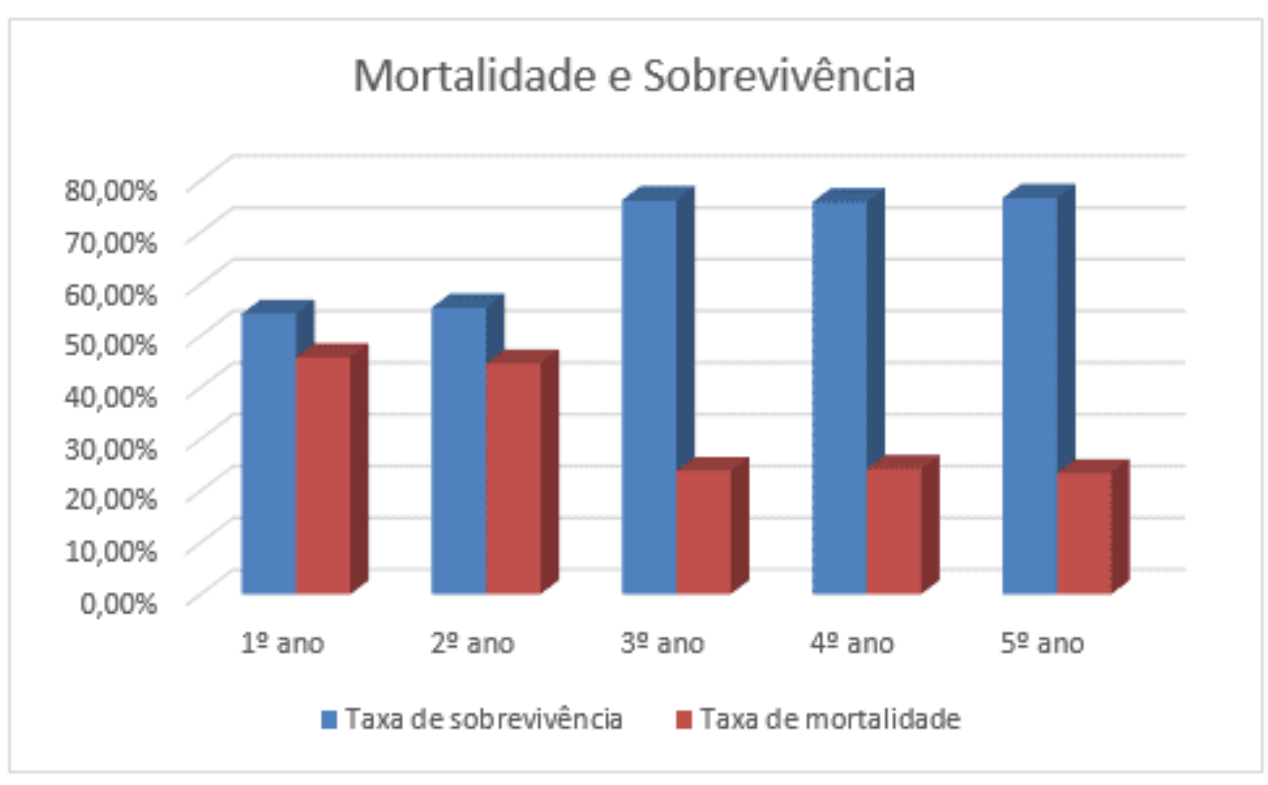

Fonte: SEBRAE 2016

Em outro estudo efetuado pelo Sebrae em 2014,(SEBRAE,2014) onde foram ouvidas 2.800 empresas, as principais causas para o fechamento das empresas foram: 
1. Falta de Planejamento prévio;

2. Gestão empresarial ineficiente;

3. Comportamento empreendedor.

Um tempo maior de planejamento tende a aumentar as chances de sucesso, pois com maior conhecimento do mercado que se irá atuar pode-se enfrentar de forma mais assertiva frentes a problemas. $O$ aperfeiçoamento de produtos e serviços tanto quando a atualização tecnológica oferecida ao setor, também contribui para o sucesso do empreendedor.É importante se ter um plano de ação com metas e objetivos claros e saber onde se quer chegar. O principal motivo para o fechamento das empresas estudadas foi a falta de capital de giro ou lucro, (investimento inicial necessário para os primeiros 5 anos de sobrevivência de uma empresa).Apesar dos sentimentos negativos e da perda financeira que ficam após o fechamento, grande parte empreendedores voltam a empreender (45\%), como autônomos (25\%) ou donos de outras empresas (20\%). (SEBRAE 2016)

Gráfico 2 - Mortalidade e sobrevivência de empresas

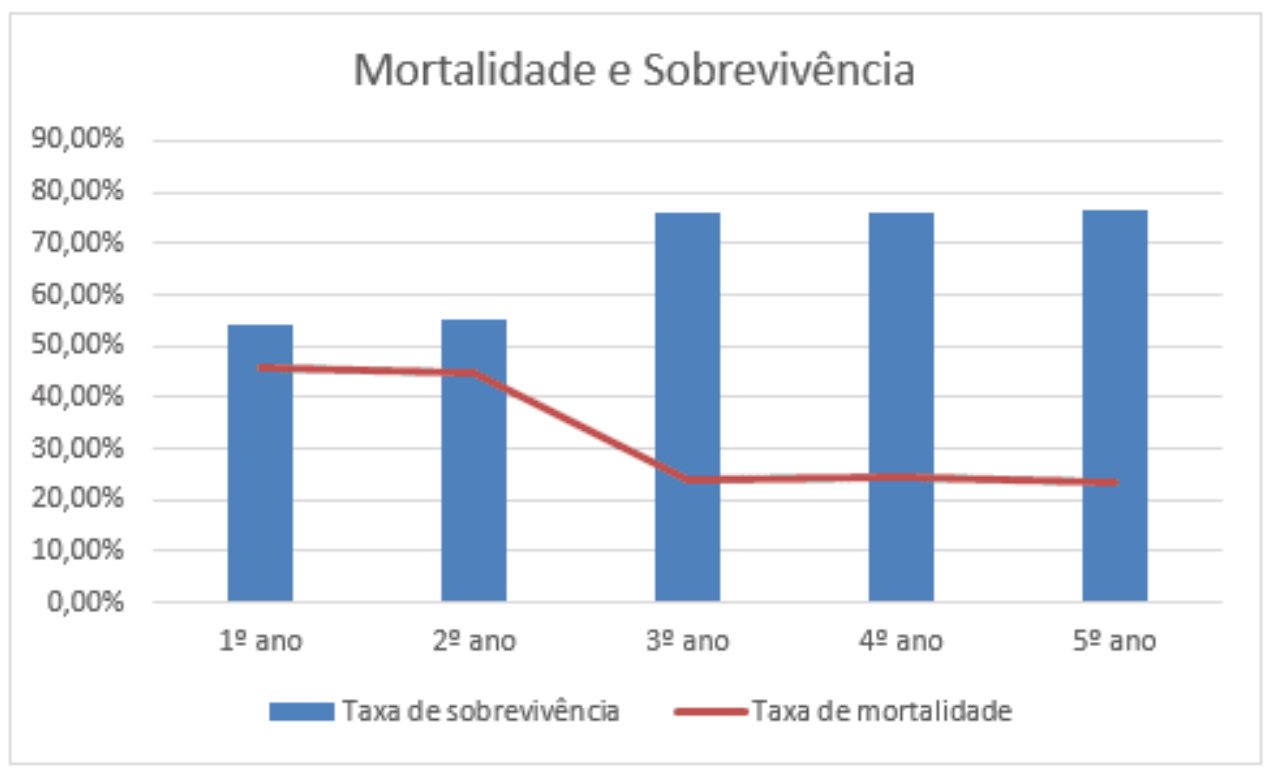

Fonte: SEBRAE 2016 
A título de ilustração, passaremos agora a um relato de caso de um empreendedor do segmento para que possamos utilizar como base da nossa análise SWOT em conjunto com as demais informações já apresenta

\section{RELATO DE CASO}

Passamos agora ao relato de caso de uma empresa que se constituiu em 2013 e que, como tantas outras, teve um desfecho indesejado, vindo a fechar oficialmente em 2017.A empresa foi idealizada com auxílio de consultoria do SEBRAE seguindo um plano de negócio. Embora a situação econômica do país fosse desfavorável naquele ano, o mercado de Pets se mostrava promissor e uma garantia de renda caso o país entrasse em uma recessão econômica no setor de contratação formal, do qual os empreendedores eram integrantes como empregados formais no regime de CLT.

Segundo estudo do Sebrae 2007. A dedicação integral ao negócio é fundamental para seu andamento, para $70 \%$ dos empresários das empresas ativas a dedicação foi de $100 \%$ ao negócio, enquanto $42 \%$ em média dos empresários das empresas extintas não se dedicaram exclusivamente à empresa. Entendendo a necessidade de apresentar um diferencial que acompanhasse o comportamento dos consumidores e tutores, bem como as tendências de humanização dos animais e a consequente busca de uma melhor qualidade de vidas para estes por parte de seus tutores, os empreendedores estudaram o mercado e em consequência decidiram a área de atuação e escopo dos serviços, bem como localização e plano de negócio.

A seguir, algumas informações importantes para compreensão do caso:

Razão social: J. R. Serviços de Banho e Tosa Ltda., situada no Jd. Campo BeloSP/SP. de Propriedade RSMF e JMRG.

Data de abertura: $11 / 2013$

Capital investido: $\mathrm{R} \$ 300.000,00$

Serviços oferecidos: 
Banho e tosa com produtos diferenciados a base de florais;

Homeopatia

Cromoterapia e Aromaterapia

Acupuntura

Reiki

Massoterapia Canina

Banho de terapêuticos em ofurô com produtos bioflorais;

Hotel sem Confinamento

Day care;

Walking dog;

Aconselhamento Comportamental

Espaço Dog Lan Café

O plano de negócio fora bem elaborado, incluindo pesquisa em relação ao mercado consumidor e mercado concorrente, avaliação de potencial de localidades, capital a ser investido e tempo de retorno de capital. A escolha do local foi definida pelo serviço

a ser oferecido e poder aquisitivo da população local: Bairro do Campo Belo, zona sul da cidade de São Paulo, a de maior densidade de cães/habitantes: há 1,42 pessoa por cão. É o que mostra um estudo do Departamento de Medicina Veterinária Preventiva e Saúde Animal da USP. 
(Figura 5): Perfil do consumidor bairro Campo Belo

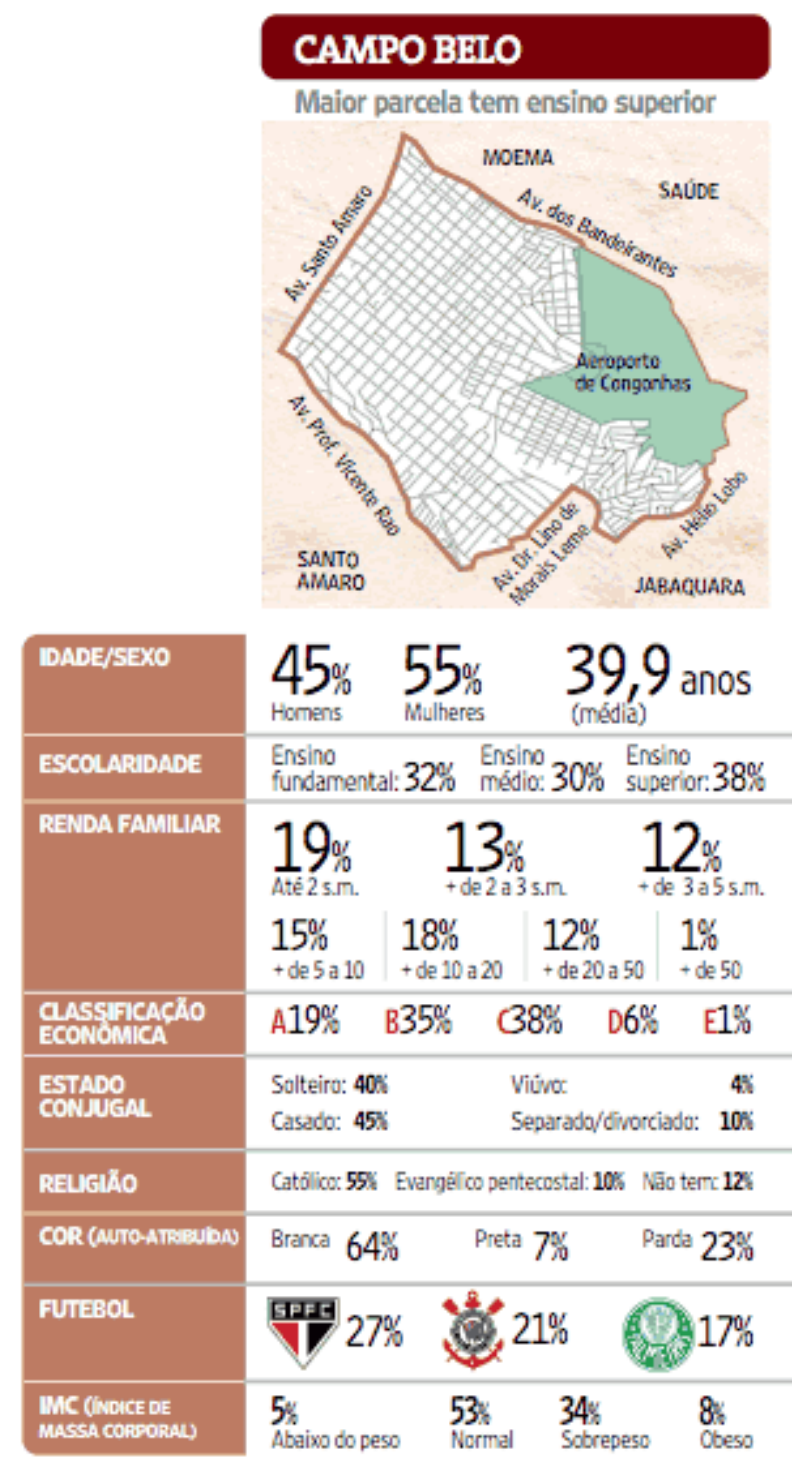

Fonte: Depto de medicina veterinária da USP

Definido o local, abertura de empresa e regularização de funcionamento, com investimento de cerca de $\mathrm{R} \$ 10.000,00$.Iniciou-se a fase de adaptação do local locado com área útil adequada em setor que permitia o tipo de comercialização e que antes era uma moradia. O investimento fora de cerca de $R \$ 150.000,00$ em obras de estruturação e mobiliários incluindo equipamentos para banho e tosa. Toda a reforma considerou as exigências da vigilância sanitária e leis da prefeitura local para funcionamento. Também considerou ter espeço adequado para todos os serviços 
oferecidos, incluindo as atividades de banho, tosa e hotel sem confinamento, com os melhores equipamentos e materiais de primeira linha, painéis de vidro fachada luminosa, decoração e segurança. A inauguração do estabelecimento se deu em 05/2014, devido a atrasos na entrega da obra de grande complexidade. Foram feitos investimentos em diversos canais de mídia, como 'internet' (sites e anúncios), panfletagem local, parcerias com clinicas veterinárias e demais comércios. O início das atividades e atendimento aos clientes já previam a necessidade de atuação dos sócios, com a atuação de apenas um funcionário treinado por eles para atuação operacional num primeiro momento, sem experiência anterior, mas amigo dos sócios, sendo os profissionais técnicos chamados à partir da demanda como parceiros "terceiros". Ao final do segundo mês já se tinha demanda para contratação de um funcionário dedicado ao atendimento ao banho e tosa, atividades de hospedagem e day care. O fluxo de caixa era administrado por um dos sócios através de um 'software' específico destinado às empresas do segmento veterinário adquirido pelo projeto, assim como toda contabilidade e pagamento de fornecedores, aluguel e compra de insumos. Foi captado no mercado cerca de $\mathrm{R} \$ 30.000,00$ de investidores simpatizantes do negócio, entusiasmados pelo plano de negócio bem realizado, infraestrutura e primeiros resultados obtidos no primeiro semestre de atividades, que Ihes garantiria um rendimento de $12 \%$ ao ano, livre de responsabilidades e de atuação direta no negócio. Bancos procurados não aceitaram aportar capital maior que 50 mil reais já utilizados nos investimentos. Segundo SEGET et al. A captação de recursos necessários a uma empresa, é de grande importância e requer atenção por parte do empreendedor, que dirá quem o ajudará na administração, que recursos utilizará, e o valor que será necessário. A boa gestão também conta para o sucesso e manutenção da empresa, garantindo decisões mais assertivas.

Como resultado das campanhas em mídia impressa e eletrônica, gradativa- mente o número de clientes se intensificou.

Com o passar do tempo e com boas experiências focada em relacionamento e qualidade de vida para os animais, os clientes tutores foram fidelizados. 
Os animais, ao contrário do que se via em outros pets, adentravam com alegria nas instalações, resultado do carinho e dedicação dos sócios, bem como confiança e qualidade de serviços.

Não obstante, observou-se que a eventual ausência dos sócios devido às suas atividades paralelas, apesar da existência de gerente administrativo e um recurso operacional, afetava intimamente as atividades.

Os clientes reportavam que quando não estavam os serviços deixavam a desejar.

As ações comerciais e administrativas cumulativas não foram supridas a altura. As vendas diminuíam a cada mês mesmo com pesados investimentos em mídia.

Os clientes fiéis reportavam a necessidade de maior proximidade dos sócios.

Em 2015 com a crise econômica e política no país instaurada, se tornou ainda mais difícil manter a sustentabilidade do negócio, havendo cada vez mais necessidade de aumento do capital de giro.

Empréstimos a juros abusivos em instituições financeiras selaram definitivamente o rumo da empresa.

Em setembro de 2015 após acumulo de cerca de $\mathrm{R} \$ 200.000,00$ em dívidas, as atividades se encerraram e o ponto, com toda a infraestrutura foi entregue ao proprietário do imóvel como pagamento de dívida contratual que considerava o retorno da estrutura do imóvel para uma condição de moradia em caso de devolução antes do término do contrato, o que implicaria em mais investimentos, impossíveis naquele cenário.

Em 2018 cerca de $R \$ 100,000,00$ ainda remanescentes das dívidas estão sendo negociados, embora a empresa tenha sido oficialmente encerrada na junta comercial em novembro de 2017. 


\section{DISCUSSÃO}

Façamos agora uma análise SWOT que considere o relato do caso e as informações anteriores para que possamos ter uma visão mais global das Fraquezas, Ameaças, Oportunidades e Forças num empreendimento similar.

Observamos que, de modo geral, o empreendimento fora bem planejado, tendo um plano de negócio (Anexo I), tendo se preocupado em garantir que a empresa tivesse uma identidade conceitual, visual, ligados a um posicionamento claro, serviços diferenciais apropriados para o contexto de saúde animal e comportamento dos tutores.

Investimento em pesquisa de mercado, em adequação e serviços de qualidade. Localização adequada, num bairro potencial e próspero do ponto de vista de consumo do tipo de serviços e perfil de público alvo.

Sócios bem preparados e pelo depoimento de clientes bem qualificados e capazes de cumprir com a entrega dos serviços prometidos, sendo capazes de fidelizar os clientes.

Mas também precisamos considerar alguns pontos: o baixo capital de giro, a pouca disponibilidade dos sócios em se dedicar ao empreendimento, os altos juros de empréstimos utilizados para a adequação do imóvel, os altos custos com divulgação, plotando estas variáveis numa análise SWOT, teríamos o seguinte desenho: 
Figura 6) Análise SWOT da empresa pós encerramento

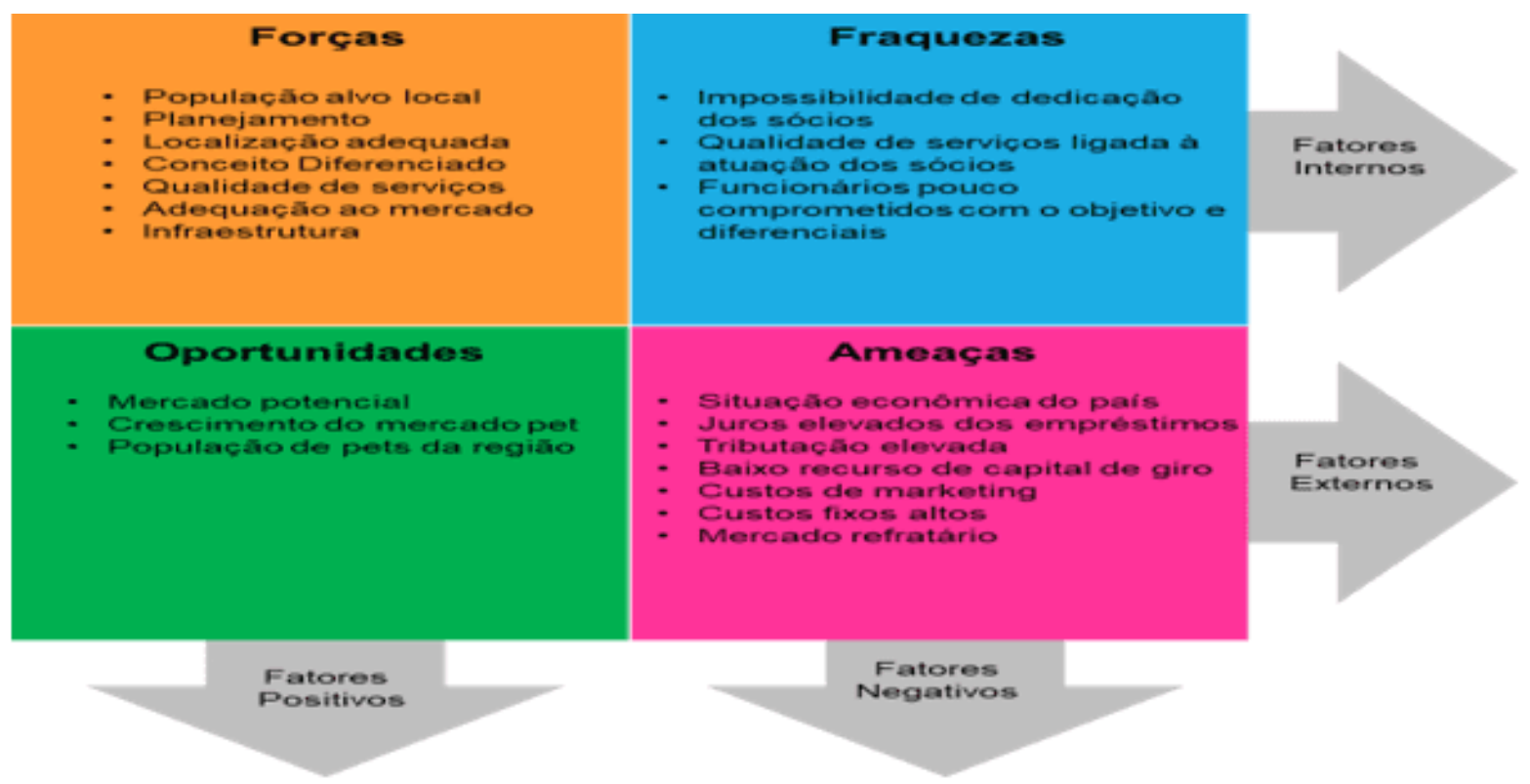

Se os sócios tivessem realizado uma análise como esta, prévia às decisões de execução do plano de negócio, talvez tivessem aguardado um pouco mais e conseguido colocar em prático com sucesso, o mesmo empreendimento em outro momento e condição de dedicação.

Segundo estudo do Sebrae 2007,(SEBRAE,2007) a dedicação integral ao negócio é fundamental para seu andamento, para $70 \%$ dos empresários das empresas ativas a dedicação foi de $100 \%$ ao negócio, enquanto $42 \%$ em média dos empresários das empresas extintas não se dedicaram exclusivamente à empresa.

Conforme relata (MOTTA ,2015), em uma empresa familiar as atividades de gestão são desenvolvidas com o tempo o controle dos custos são praticados, comparando os preços aos da concorrência. Se um lado, existe um mercado em crescimento devido ao aumento de animais nos lares e comportamento dos tutores, por outro a concorrência aumenta na mesma proporção.

Segundo (SEGET et al. Art.1, 2014) A captação de recursos necessários a uma empresa, é de grande importância e requer atenção por parte do empreendedor, que dirá quem o ajudará na administração, que recursos utilizará, e o valor que será 
necessário. A boa gestão também conta para o sucesso e manutenção da empresa, garantindo decisões mais assertivas.

Os estudos relatados atestam a necessidade da atuação da área de marketing, principalmente para uma empresa recém-criada, como a grande e maior dificuldade devido ao custo de veiculação das propagandas em mídia eletrônica, ferramentas de buscas na internet, que possuem custos altíssimos, pagos por acesso à página. Além disso, investimento em marketing tanto digital, quanto boca a boca são importantes ferramentas para ampliar a quantidade de potenciais consumidores dos serviços prestados pela empresa, seja por meio de plataformas online ou através de clientes já fidelizados, conhecidos e mesmo os inseridos no estabelecimento. Outro ponto importante a ser ressaltado fora a importante contribuição dos clientes ao relatar os problemas encontrados na ausência dos sócios. Portanto, o sucesso de uma empresa, seja para implantação ou mesmo durante o funcionamento está ligado na capacidade em ouvir as sugestões e opiniões dos clientes e sua capacidade de redirecionar ações para a garantia de sucesso. Mesmo com a desaceleração econômica, o mercado pet ainda encanta pela resiliência diante dos índices de desemprego e da corrosão da renda da população pela inflação. "Mesmo crescendo mais devagar, o mercado de animais de estimação representa $0,38 \%$ do produto interno bruto (PIB) e já é maior do que a linha branca de geladeira e fogão", diz José Edson Galvão de França, presidente executivo da Associação Brasileira da Indústria de Produtos para Animais de Estimação (Abinpet). Conforme publicação da Revista Você S.A. em Publicado em 20 jan 2017, (VOCE S/A, 2017) empresas como MSD Saúde Animal, que no ano passado faturou 576 milhões de reais no Brasil, reforçam que a qualificação da mão de obra torna-se cada vez mais essencial para o setor e não economizam, tendo investido cerca de 1,5 milhão de reais na capacitação de cerca de 400 funcionários em julho de 2017, entre proprietários de estabelecimentos e distribuidores, reunidos por uma semana num resort na Praia do Forte, na Bahia, para debater a importância da prevenção de doenças nos animais, (POLLI,M revista exame 2017). Também a fabricante global de produtos farmacêuticos animais de nome Zoetis, fabricante global de produtos farmacêuticos animais atua em inovações para atender às exigências dos tutores de pets, agora investindo em um remédio sem 
corticoide para romper o ciclo de coceira e inflamação associado às alergias, segmento que já proporcionou a esta organização no último trimestre de 2017 um faturamento de cerca de 56 milhões de reais no Brasil.(POLLI M. REVISTA EXAME, 2017). Rações medicamentosas específicas para apoio terapêutico no tratamento de doenças renais, cardíacas e de pele são outro segmento próspero. Os valores são altos, mas continua em alta, em especial no combate à obesidade. As contratações nestas empresas também aumentam com o aumento de consumo no setor. Os investimentos no Brasil crescem pesadamente em empresas como a Mars, norteamericana detentora das marcas Royal Canin, Pedigree e Whiskas, que no ano de 2017 aportou 250 milhões de reais na área de petcare, incluindo a contratação de executivos de peso, com benefícios atrativos e diferenciados, com em treinamentos para sustentação da liderança para melhoria da performance de gestão das pessoas e dos investimentos em marketing, pesquisa e desenvolvimento. Com os novos avanços, a medicina veterinária está mais cara. Também observamos o crescimento de ofertas em planos de saúde pet, visto que custos com internação e medicamentos podem rapidamente chegar à casa dos cinco dígitos. No Brasil há planos à partir de $\mathrm{R} \$ 50,00$ reais mensais atendendo nas principais capitais do Sul e Sudeste. A Porto seguro, por exemplo, que possui cerca de 28000 corretores, cresce a sua base de "vidas pet", contando com 22000 animais segurados praticamente 700 veterinários credenciados em Belo Horizonte, Rio de Janeiro, São Paulo e região metropolitana, além de Piracicaba e Campinas, no interior paulista e investimentos que devem ultrapassar 10 milhões de reais pensando em expansão para outros mercados. Podemos citar ainda investimentos no setor da saúde, em estudos com células tronco, rede de hospitais veterinários de ponta, centros especializados em dermatologia, oncologia e outros.

\section{CONCLUSÃO}

Embora os estudos indiquem boas perspectivas do mercado, a realidade é bem diferente. O ramo exige uma dedicação exclusiva ao negócio, sendo que a parte administrativa e comercial deve ser feita exclusivamente pelo proprietário para tomadas de decisões rápidas e objetivas. $\mathrm{O}$ mercado se mostra muito flutuante e 
dinâmico, qualquer oscilação, seja por aumento de concorrência, alterações de política econômica e mudança de governo, administração inadequada, pode influenciar diretamente no sucesso da empresa. O que pode se observar é que (Gráfico 2) a sobrevivência das empresas depende de um investimento alto nos dois primeiros anos e ainda significativo no terceiro ano. Como já vimos, a taxa de mortalidade confirma (gráfico) que $55 \%$ das empresas encerram as atividades nos dois primeiros anos e ainda $25 \%$ encerram as atividades após o terceiro ano.

(Gráfico 2) - Taxa de sobrevivência das empresas.

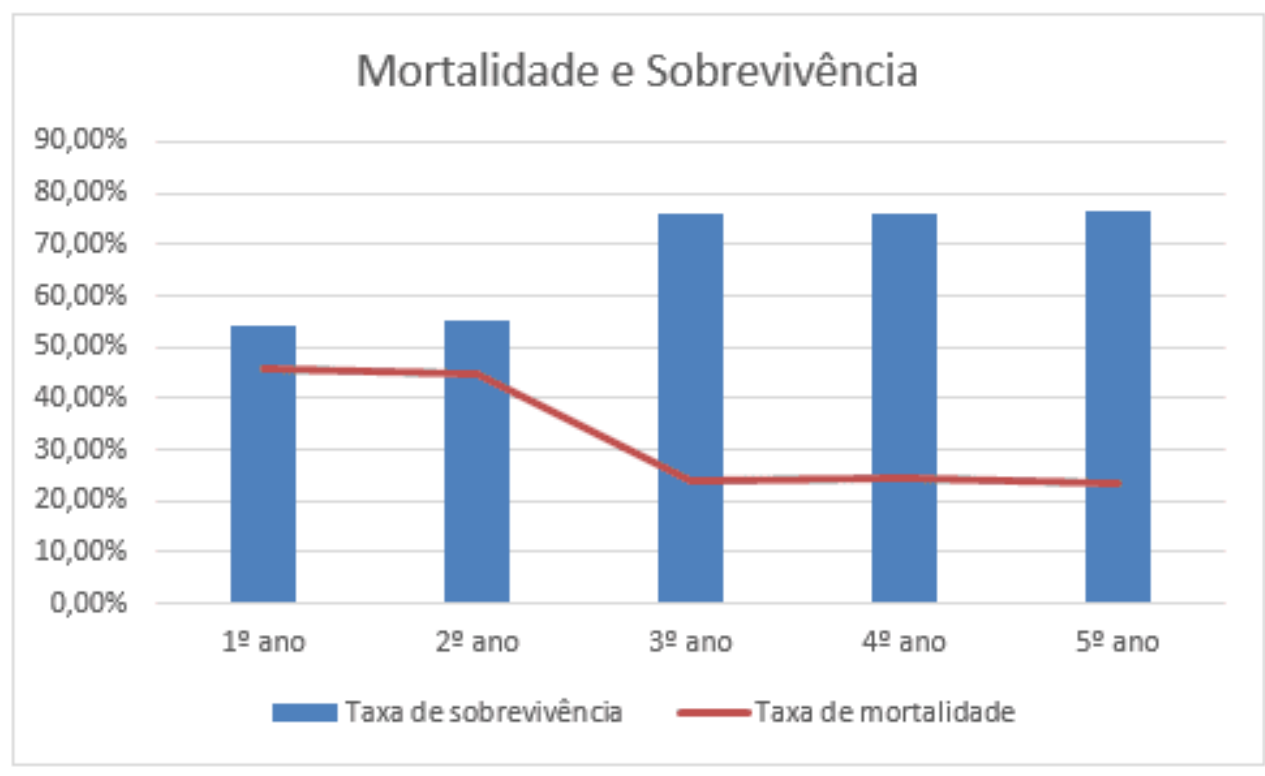

Fonte: SEBRAE 2016

Visando o melhor desempenho no segmento, é importante que a empresa ofereça aos clientes produtos que possam diferenciar o estabelecimento dos demais, o que contribui para que possa conquistar e também ter fidelização por parte dos clientes. Mas é necessário que os recursos humanos envolvidos estejam devidamente engajados e compromissados com os objetivos e metas, além dos seus sócios, é claro. É preciso que as empresas tenham visão sistêmica quanto ao entendimento, seja sobre a composição, aspectos envolvidos, necessidades e expectativas do cliente, assim como a realização de tratamentos, oferta dos produtos, entre outros. Quando se trata de administração de empresas, seja de pequeno ou grande porte, 
atenção deve ser priorizada as mudanças de hábitos dos clientes, por meio de novos canais de comunicação e distribuição de produtos e serviços, através de uso de estratégias que são dispostas pelos concorrentes, em especial quando são levadas em consideração as mudanças do mercado (GUIDI et al., 2018). Sabe-se que consumidores tem disposição a sempre pagar mais por um produto ou serviço, desde que este venha a suprir as suas necessidades. Contudo, não se utiliza o preço como único argumento de venda, uma vez que, a empresa precisa traçar o próprio caminho, possuindo competência no atendimento aos clientes, o qual acarretará lucros e mantença do estabelecimento no mercado (MAGALHÃES, 2005). Sabe-se que na sociedade atual, a internet se faz ferramenta de trabalho, contribuindo para maior divulgação dos serviços prestados, qualidade e preferência dos clientes. Contudo, por meio do advento da internet teve aumento também quanto a competitividade e produtividade. Assim, é importante que para o modelo de organizações para o futuro, tenham por base a coleta e tratamento de dados para auxílio nas tomadas de decisões, tirando vantagem em relação a concorrência perante a nova economia. Por fim, podemos concluir que por mais que tenhamos fatores positivamente relevantes para o negócio em nossa lista de "forças" e "oportunidades", não podemos ver com menor importância as "fraquezas" e "ameaças". Em última análise, três fatores críticos de sucesso foram responsáveis pelo desfecho desfavorável no relato de caso apresentado:

- Dedicação dos sócios;

- Engajamento e preparo dos funcionários;

- Capital de giro insuficiente para os dois primeiros anos de funcionamento;

Podemos concluir que no segmento pet, assim como em outros segmentos do mercado e, porque não dizer da vida, devemos nos apropriar de ferramentas que possam nos auxiliar na tomada de decisão de maneira a nos proporcionar a visão adequada sobre o cenário de forma abrangente, como um sobrevoo que seja capaz de visualizar em médio e longo prazo os desafios e dificuldades a serem enfrentadas. O mercado atrativo e crescente dos pets, pode ser uma grande armadilha. 
A sobrevivência das empresas no ramos de pet shop, a exemplo do relato de caso da presente pesquisa, deve considerar uma análise prévia detalhada de suas fraquezas e das ameaças para seu negócio, de maneira a atuar preventivamente. A exemplo do relato do caso, não basta ter um planejamento prévio embasado nos estudos e tendência de mercado, que se mostravam e ainda hoje se mostram significativos e atraentes. Deve-se considerar que é preciso alto investimento de capital de giro e onerações de juros de empréstimos, se houver. É necessária a dedicação em tempo integral, capital humano e investimentos massivos em mídia, nos três primeiros anos e, ainda assim, a possibilidade de não se ter sucesso supera os $25 \%$ de empresas que encerram as atividades após este período. Dificilmente se encerra uma empresa sem ônus, conforme relato, o prejuízo se equiparou ao investimento inicial, pode-se concluir que o investimento total na empresa foi de meio milhão de reais, e os mesmos meios milhão de reais em prejuízo. Assim, vale a pena avaliar se neste cenário, investir as economias familiares para empreender é suficiente ou se é necessário buscar o aporte financeiro para suportar boas ideias, de modo a prover a possibilidade de dedicação integral ao negócio.

\section{REFERÊNCIAS}

ABINPET. Disponível em: <http://abinpet.org.br/site/mercado/ - acessado em12/05/2018>

AFONSO, T.; BERDASCO, L.; MEDEIROS, T.; REJOWSKI, M. Mercado pet em ascensão - hotelaria para cães e gatos em São Paulo. Revista Brasileira de Pesquisa em Turismo, v. 2, n. 4, p. 102-123, 2008.

CASAROTTO C. Disponível em: <https://marketingdeconteudo.com/como-fazer-umaanalise-swot/ - acessado em 04/05/2018>

COELHO, T. D.; SANTOS, A. E. W. Marketing boca a boca: um estudo de caso no pet shop bicho guloso. III Encontro Centro-Oeste de História da Mídia. [Anais...]. 2016. Campo Grande, Mato Grosso. 
DEPARTAMENTO DE MEDICINA VETERINÁRIA PREVENTIVA E SAÚDE ANIMAL disponível em: <http://vps2.fmvz.usp.br/ - acessado em 15/06/208)

\section{ELIZEIRE, M. B. Expansão do mercado Pet e a importância do Marketing na} medicina veterinária. 2013. Monografia (Graduação em Medicina Veterinária) Universidade Federal do Rio Grande do Sul. Porto Alegre.

EM

NACIONAL

Disponível

em

$<w w w . e m . c o m . b r / a p p / n o t i c i a / n a c i o n a l / 2016 / 07 / 28 /$ interna_nacional,788614/no-

brasil-44-3-dos-domicilios-possuem-pelo-menos-um-cachorro-e-17-7.shtml-

acessado em 15/07/2018>

EUROMONITOR Disponível em: <http://www.euromonitor.com/ - acessado em 15/07/2018)

GUIDI, P. G.; FACIOLI, L. M.; DONZELLI, O. O mercado de pet shop na cidade de Franca-SP. 2018. Disponível em: < $<$ http://periodicos.unifacef.com.br/index.php/forumadm/article/viewFile/662/676 Acesso em 26 mai 2018.>

KOTLER, P; KELLER K.L. Administração de Marketing. 12 ed. São Paulo: Prentice Hall, 2006.

MAGALHÃES, J. C. G. Administrando um pet shop. Pós-graduação (Latu sensu). $42 f$. 2005. Universidade Candido Mendes. Rio de Janeiro

MARIANA POLLI REVISTA EXAME Disponível em: $<$ https://exame.abril.com.br/carreira/mercado-pet-cresce-gracas-a-mudancas-nocomportamento-dos-donos-de-animais-de-estimacao/ - acessado em 15/05/2018>

NEGOCIO PET Disponível em: <https://revistanegociospet.com.br/tags/mercado-pet2018/ - acessado em 22/0/2018> 
REVISTA EXAME Disponível em: <https://exame.abril.com.br/carreira/mercado-petcresce-gracas-amudancas-no-comportamento-dos-donos-de-animais-deestimacao>

SEGET disponível em: <https://www.aedb.br/seget/arquivos/artigos11/1143.pdf acessado em 15/07/2018>

SEBRAE

em:

<https://m.sebrae.com.br/Sebrae/Portal\%20Sebrae/UFs/SP/Anexos/causa_mortis_2 014.pdf - acessado em 14/06/2018>.

SEBRAE. 2016. Disponível em: <http://www.sebrae.com.br/sites/ PortalSebrae/ufs/sp/cursos_eventos/pet-shop-um-mercado-em-ascensao\% 2C26910deba487c510VgnVCM1000004c00210aRCRD - acessado em 15/06/2018>

SEBRAE. Disponível em: <http://www.sebrae.com.br/Sebrae/Portal\%20Sebrae/ Anexos/sobrevivencia-das-empresas-no-brasil-relatorio-2016.pdf - acessado em 15/06/2018>.

SEBRAE

em:< http://www.bibliotecas.sebrae.com.br/chronus/ARQUIVOS_CHRONUS/bds/bds.nsf/8 F5BDE79736CB99483257447006CBAD3/\$File/NT00037936.pdf - acessado em $15 / 06 / 2018>$

SSPET disponível em: <https://sspet.com.br/blog/dados-do-mercado-pet-no-brasil/ acessado em 30/05/2018>

UNESC

em:

<HTTP://REPOSITORIO.UNESC.NET/BITSTREAM/1/4094/1/DANIEL20DA20SILVA 20MOTTA.P Um estudo em uma Pet Shop. 2015. - acessado em 28/06/2018>

Enviado: Setembro, 2018.

Aprovado: Setembro, 2019. 